\title{
Correction to: Improvement of the Operational Budgeting Model at the Industrial Enterprise
}

\author{
L. V. Iurieva, E. R. Sinianskaia, and O. V. Savostina
}

\section{Correction to:}

Chapter 21 in: D. B. Solovev et al. (eds.), Proceeding of the International Science and Technology Conference

“FarEastCon 2019”, Smart Innovation, Systems

and Technologies 172, https://doi.org/10.1007/978-981-15-2244-4_21

In the original version of the chapter, the following belated corrections have been incorporated: The author name "O. V. Sinianskaia" has been changed to "O. V. Savostina" in the Frontmatter, Backmatter and in Chapter 21. The correction chapter and the book have been updated with the change. 